\title{
A Research on Chinese Consumers' Using Intention on 3G Mobile Phones
}

\author{
Matthew Tingchi Liu', and Zhizhong Chen ${ }^{2}$ \\ 1 Faculty of Management and Administration, Macau University of \\ Science and Technology, Avenue Wai Long, Taipa, Macau \\ matthewliu@must.edu.mo \\ 2 School of Economics and Management, Tsinghua University, \\ 100084 Beijing, People's Republic of China \\ Chenzz03@mails.thu.edu.cn
}

\begin{abstract}
With the explosion of technology development, information appliance (IA) and digital devices (DD) become more and more popular these years. And the development of the third generation (3G) mobile phone is viewed as the most potential profitable product in the next decade. However, $3 \mathrm{G}$ mobile phone is confronting its promotion bottleneck. By using diffusion of innovation and lifestyle theory, hence, this study aims to examine the factors influencing adopting $3 \mathrm{G}$ mobile phone intention. Result shows only "technology cluster" is significantly related to adoption intention among four variables examined in this study.
\end{abstract}

\section{Introduction}

Under the technological convergence trend, third generation (3G) mobile phone is viewed as the most potential profitable product in the next decade. Except for traditional telecommunication, consumers can do many things such as accessing to internet, receiving/sending email, watching TV, listening radio and MP3, taking photos, and even remote control appliance via $3 \mathrm{G}$ mobile phone.

There were many researches related to the trend of $3 \mathrm{G}$ mobile phone industry or product improvement in China, but very few researches were conducted about $3 \mathrm{G}$ mobile phone adoption process and the factors influencing the intention to adopt $3 \mathrm{G}$ mobile phone. If it is made clear that the key factors in the adoption process, it will do help to the diffusion and market exploration of technology-integrated products. Rogers' Diffusion of Innovation was used to research the diffusion process of the new products very often. In this study, in order to emphasize the consumers' personality traits and social characteristics, we not only adopt Rogers' Diffusion of Innovation, but also lifestyle theory in marketing field. By describing consumers' lifestyle, this research hopes to figure out the factors that influence the $3 \mathrm{G}$ mobile phone adoption intention and find 
out the most important cause during bottleneck stage of $3 \mathrm{G}$ mobile phone diffusion processes.

\section{Literature Review}

\subsection{Devolvement of 3G mobile phone}

$3 G$ refers to the third generation of developments in wireless technology, especially mobile communications. The third generation, as its name suggests, follows the first generation $(1 \mathrm{G})$ and second generation $(2 \mathrm{G})$ in wireless communications. $3 \mathrm{G}$ mobile in the shape of UMTS (Universal Mobile Telecommunications System) with WCDMA (Wideband Code Division Multiple Access) as radio access technology is already a reality.

$3 \mathrm{G}$ offers the potential to keep people connected at all times and in all places. However, there are many factors contributing to why $3 \mathrm{G}$ mobile do not spread. The two main reasons are technology and market.

First, the $3 \mathrm{G}$ mobile telecommunication licenses are not easy to get. Until August 2005, there are only 111 licenses in the whole world, strong competition exists among corporations to acquire licenses in $3 \mathrm{G}$ mobile. There are three main methods to release the licenses, Auction, Comparative Selection and Hybrid [1]. Auction is widely utilized in Europe for the licenses. But in mainland China, the government has not decided which method to use when selecting the mobile operators. The delay of the license distribution means the introduction of $3 \mathrm{G}$ will take longer.

Second, the three models in $3 \mathrm{G}$ telecommunication including WCDMA mainly in Europe, CDMA2000 in US, and TD-SCDMA mainly in China, attribute to the uncertainty of its development.

Furthermore, the low production of the $3 \mathrm{G}$ mobile handsets restrains the widespread adoption of $3 \mathrm{G}$ mobile. Of the several industry segments of $3 \mathrm{G}$ mobile, handset is always the weak one [2]. Until now, multimedia handsets developed for the new generation of networks have been not enough for customers to select and too expensive for mainstream adoption.

Last but not least, the shortcomings of $3 \mathrm{G}$ itself became a problem for its promotion. The disadvantage that it could not support high speed IP is an important weakness [3]. The competition from other technologies makes situation even worse as well. A main competitor is $4 \mathrm{G}$ a wireless service whose mobile ability is not good as $3 \mathrm{G}$ but has a better capacity. It could be possible that customer bypass $3 \mathrm{G}$ and directly adopt $4 \mathrm{G}$.

\subsection{Diffusion of Innovations (DOI) Mode}

Diffusion of innovation (DOI) theory refers to how people adopt new idea, product, or practice, and what factors would affect this adoption process. The original diffusion research was done as early as 1903 by the French sociologist Gabriel Tarde who plotted the original S-shaped diffusion curve. Tardes' 1903 Sshaped curve is of current importance because "most innovations have an Sshaped rate of adoption" [4]. 
Diffusion is the "process by which an innovation is communicated through certain channels over a period of time among the members of a social system" [4]. Rogers [4] argued that it consists of four stages: invention, diffusion (or communication) through the social system, time and consequences. The information flows through networks.

Within the diffusion process, adopters could be separated into five categories: (1) innovators, (2) early adopters, (3) early majority, (4) late majority, and (5) laggards. These categories follow a standard deviation-curve, very little innovators adopt the innovation in the beginning (2.5\%), early adopters making up for $13.5 \%$ a short time later, the early majority $34 \%$, the late majority $34 \%$ and after some time finally the laggards make up for $16 \%$.

Theory on the diffusion of innovations has been used to study the spread of new ideas and practices for over 50 years in a wide variety of settings. Most studies have been retrospective, and most have neglected to collect information on interpersonal communication networks/ device [5]. However, several studies both quantitative and qualitative have been conducted focusing on the interdependencies of organizational and technological characteristics and with the aim of generating models for intervention [6].

Rogers [4] suggested that the diffusion process will become S-shaped curve according to the speed of new product adoption. In other words, in the beginning of adoption there are few people, and when the time passes, it will be adopt by more people. During the process of new product diffusion, critical mass is an important criterion. Only after the amount of adoption people breaks through the critical mass, new product will diffuse very quickly in the society, till popular.

Thus, the content of "Diffusion of Innovation" is not only related to the diffusion process of new products, but also the characteristics of individuals will influence the diffusion process. It will be difficult to test every variable in the model because there are many variables that influence the innovation diffusion process; even the technology advancement of the industry sometimes plays a critical role during that process. According to the four elements of Rogers' DOI model, the characteristics of innovation or communication channels all related to consumers, because the characteristics of innovation should be examined by people and the uses of media also due to the behaviors of human beings. So, this study tends to investigate the factors influencing the intention to adopt $3 \mathrm{G}$ mobile phones.

\section{Methodology}

\subsection{Development of Questionnaire}

The questionnaire includes five parts. In the first part, we investigate whether the respondent use $3 \mathrm{G}$ mobile phone or not. If the answer is "No", we continually ask their further adoption intention. The answer 0 (zero) means "won't adoption", and 1 to 5 stands for levels of adoption intention; the higher the number is, the higher the adoption intention is. As to those who have already used $3 \mathrm{G}$ mobile phone, numbers from 6 (less than half year) to 10 (over 2 years) are on behalf of different time period used $3 \mathrm{G}$ mobile. Thus, we use $0-10$ to present the level of 
adoption intention for $3 \mathrm{G}$ mobile phones. The higher the number is, the higher adoption intention is.

In the second part, we tested the respondents' traits of technology cluster. Because $3 \mathrm{G}$ mobile phones are personal technological products, we conclude seven products that are featured in high technology and individuality attributes, including PDA, notebook, digital camera, MP3, DVD player, digital video (DV) and wireless internet device after reviewing literature and technological magazines.

In third part, we collected the situation how respondents use media. We ask respondents the hours/amount per day they watch TV, listen to radio, read newspapers/ magazines, and surf internet. We tend to know respondents' media exposure degree to the communication channels.

The fourth part is about lifestyle. We adopt lifestyle scale [7], with Likert 5points format, which was used in China for new media technology adoption research. The last part is about demographic information, including gender, age, education, personal monthly income and household monthly income. Those are factors of socio-economic status. In order to increase the face validity and avoid the confusion of items, we conducted pretest before formal survey.

\subsection{Sampling}

Our samples were selected from five major cities in China: Beijing, Shanghai, Guangzhou, Chongqing, and Shenzhen.

The random sampling conducted by telephone in five cities was based on the yellow pages issued by China Telecom in 2005. The subjects were focus on adults, so people who less than 18 years old, if contacted, would be interviewed further. In order to make respondents understand $3 \mathrm{G}$ mobile phone precisely, interviewers will explain the definition and characteristics of $3 \mathrm{G}$ mobile phone to respondents in the beginning. Finally, 620 respondents were interviewed, while the qualified respondents are 280 people. Therefore, the successful respondent rate is $45.2 \%$.

\section{Data Analysis}

\subsection{Description of respondents}

Within all qualified respondents, there are 130 male (46\%) and 150 female (54\%). Most subjects are 26-35 years old (31\%) and 36-45 years old (29\%). 50\% subjects have bachelor degree and $30 \%$ subjects are graduated from senior high school. $24 \%$ subjects have more than 10,000 RMB and $18 \%$ subjects have 5,000 8,000 RMB. The distribution of household monthly income centered on 10,000$15,000 \mathrm{RMB}(24 \%)$ and more than $30,000 \mathrm{RMB}(16 \%)$. Regarding the $3 \mathrm{G}$ usage style, there were 26 users $(9.3 \%), 104$ potential users $(37.1 \%)$, and 150 non-users $(53.6 \%)$. 


\subsection{Factor Analysis of Lifestyle}

The lifestyle questionnaires consisted of 22 statements from Leung [7], which has been referred by many other researches. To examine the reliability of five constructs, Cronbach's alpha was computed. Although there is no precise range existing to evaluate Cronbach's alpha, Nunnally presented a rule of thumb [8], stating that alpha levels higher than 0.50 indicate internal consistency among the items of a scale.

Further, a principal-component factor analysis was performed on the lifestyle statements to assess the stability of the dimensions across. As a result, five factors emerged as our expectation, which were named as fad-chasing, lifefulfilling, pleasure-enjoying, foreign product-preferring, and media-trusting. The five factors explained nearly or above $57.039 \%$ of the total variance.

\subsection{Pearson's Correlation Analysis}

\section{Socio-economic Status}

As to the relationships between socio-economic variables and intention to adopt $3 \mathrm{G}$ mobile phone, we used Pearson's correlation analysis to verify. The relationships between intention to adopt and age, educational status, personal monthly income, and household monthly income were significant. Therefore, we could conclude that the subjects who are younger or have higher socioeconomics status have higher intention to adopt $3 \mathrm{G}$ mobile phone.

\section{Technology Cluster}

As to the relationships between the technology cluster and intention to adopt $3 \mathrm{G}$ mobile phone, the result presented a positive correlation $(r=.445)$. Therefore, the subjects who have high technology-cluster characteristics have higher intention to adopt $3 \mathrm{G}$ mobile phone. It is thus clear that people who have high technology-cluster characteristics and hence are brave in new things are relatively easy to accept $3 \mathrm{G}$ mobile phone.

\section{Media Use}

As to Pearson's correlation analysis of media use and intention to adopt $3 \mathrm{G}$ mobile phone, most mass media were not significantly related to willing to adopt but internet was $(r=316)$. Since technology products like $3 \mathrm{G}$ mobile phone are exposed to internet media, which are information-orientated, and the usage of internet and $3 \mathrm{G}$ mobile phone are both high-involved personal behaviors, exploring the internet is positively related to the adoption $3 \mathrm{G}$ mobile phone.

\section{Lifestyle}

The results of lifestyle variables and intention to adopt $3 \mathrm{G}$ mobile phone were listed in Table 5. Only life-fulfilling was significantly and positively related to intention to adopt $(r=315)$. The reason of this result may be that people who like to learn new knowledge and are hard to study are relatively familiar with product characteristics and current information of $3 \mathrm{G}$ mobile phone.

Table1. Pearson's Correlation of $3 \mathrm{G}$ use intention with socio-economic status, media use, and lifestyle

\begin{tabular}{|c|c|c|}
\hline Item & Sig. & Pearson's Correlation \\
\hline Age & 0.029 & $-0.185^{*}$ \\
\hline Educational status & 0.001 & $0.284^{* *}$ \\
\hline Personal monthly income & 0.001 & $0.287^{* *}$ \\
\hline
\end{tabular}




\begin{tabular}{|c|c|c|}
\hline Household monthly income & 0.000 & $0.313^{* * *}$ \\
\hline Technology Cluster & 0.000 & $0.445^{* * *}$ \\
\hline Media use: TV & 0.452 & -.064 \\
\hline Media use: Radio & 0.751 & 0.027 \\
\hline Media use: Newspaper & 0.794 & 0.022 \\
\hline Media use: Magazine & 0.070 & 0.154 \\
\hline Media use: Internet & 0.000 & $0.316^{* * *}$ \\
\hline Lifestyle: fad-chasing & 0.205 & 0.108 \\
\hline Lifestyle: life-fulfilling & 0.000 & $0.315^{* * *}$ \\
\hline Lifestyle: pleasure-enjoying & 0.085 & 0.146 \\
\hline Lifestyle: foreign product-preferring & 0.501 & 0.057 \\
\hline Lifestyle: media-trusting & 0.552 & 0.051 \\
\hline
\end{tabular}

$* \mathrm{P}<0.05 * * \mathrm{P}<0.01 * * * \mathrm{P}<0.001$

\subsection{Hierarchical regression analysis}

The hierarchical regression model estimates are provided in Table 6 . The Rsquare of the whole model was $28.5 \%$. Tests for the unstandardized $\beta$ coefficient indicated that only technology cluster has significant influence on willing to adopt $3 \mathrm{G}$ mobile phone, but the R-square was only $6.9 \%$. Other variables such as socio-economic variables, media use, and lifestyle did not have significant influences on willing to adopt.

Table2. Hierarchical regression model of the influence of independent variables on intention to adopt $3 \mathrm{G}$ mobile phone

\begin{tabular}{|c|c|c|c|}
\hline \multicolumn{2}{|c|}{ Independent variables } & Unstandardized $\beta$ & Sig. \\
\hline \multirow{6}{*}{$\begin{array}{l}\text { Socio- } \\
\text { Economic }\end{array}$} & Sex & -.112 & .179 \\
\hline & Age & -.105 & .276 \\
\hline & Education & .003 & .982 \\
\hline & Individual Income & .026 & .817 \\
\hline & Household Income & .038 & .721 \\
\hline & $\mathrm{R}^{2}$ & \multicolumn{2}{|l|}{.163} \\
\hline \multirow{6}{*}{ Media Use } & TV & -.021 & .807 \\
\hline & Radio & .009 & .911 \\
\hline & Newspaper & .005 & .951 \\
\hline & Magazine & -.023 & .796 \\
\hline & Internet & .099 & .298 \\
\hline & $\mathrm{R}^{2}$ & \multicolumn{2}{|l|}{.190} \\
\hline \multirow{2}{*}{$\begin{array}{c}\text { Technology } \\
\text { Cluster }\end{array}$} & High-tech product-owning & .336 & $.001^{* * *}$ \\
\hline & $\mathrm{R}^{2}$ & \multicolumn{2}{|l|}{.259} \\
\hline \multirow{6}{*}{ Life-style } & fad-chasing & -.067 & .508 \\
\hline & life-fulfilling & .157 & .113 \\
\hline & pleasure-enjoying & -.021 & .827 \\
\hline & foreign product-preferring & .081 & .342 \\
\hline & media-trusting & .030 & .730 \\
\hline & $\mathrm{R}^{2}$ & \multicolumn{2}{|l|}{.285} \\
\hline
\end{tabular}

$* * * \mathrm{P}<0.001$ 


\section{Conclusion and Further Directions}

\subsection{Conslusion}

The result showed that socio-economic status has no impact on the intention to adopt $3 \mathrm{G}$ mobile phones. It contradicts to many past researches $[9,10]$. Combined the findings with Jeffres and Atkin's [11] study on the adoption of ISDN and Li's [12] study on the adoption of cable TV shopping, that revealed that socio-economic status doesn't have definitely correlation with the adoption of those innovations.

Technology cluster is to test the owning of other products with similar features on adoption. In this study, we raise seven products that have similar senses of technology and the claims of usages. In regression analysis, it is confirmed that technology cluster has positive and significant relationship with intention to adopt $3 \mathrm{G}$ mobile phones. In other words, the more someone owns products with similar features or functions to $3 \mathrm{G}$ mobile phones, the higher the intention to adopt $3 \mathrm{G}$ mobile phones.

As to the use of media dimension, the use of $T V$, radio, newspaper, magazines has no impact on the intention to adopt $3 \mathrm{G}$ mobile phones. The result is quite opposite to some past studies $[13,14]$. But there are some studies pointed out that the use of media doesn't have definitely relationship with the adoption of innovation [15]. Therefore, predict the adoption of innovation by only considering the use of media is not enough, maybe it more convincing to also examine the contents that media channels provide.

Lifestyle, which describes the consumer's social and psychological traits, can be divided by five dimensions: fad-chasing, life-fulfilling, pleasure-enjoying, foreign product-preferring and media-trusting [7]. Those dimensions have no predict ability to the intention of adopt of $3 \mathrm{G}$ mobile phones in this study. There are 300 items in the development of AIO scale in the beginning. As time goes by, there are two major kinds of scales, including general and specific lifestyle, were developed [16]. In this study, due to the resource and time constraints, we only adopt five dimensions of general lifestyle scale which maybe not suitable to the adoption of $3 \mathrm{G}$ mobile phones. We might get more valued findings if taking other or some specific dimensions of lifestyle to measure.

Although the analysis in this study only revealed technology cluster has significant relationship with $3 \mathrm{G}$ mobile phones adopt intention, personal motive is also a critical factor to adoption of new products. Rogers also pointed out that during the diffusion process of innovation, the features of the innovation that satisfied personal needs of motives would raise the willingness to adopt, contribute to decision making and cause the adoption behaviors [4]. Thus, 3G mobile phone producers should adjust the functions of their products according to consumers' real needs.

\subsection{Research Limitation and future direction}

Due to time and cost limitation, this research adopt telephone interview with smaller sample size in five major cities in China. Future research may conduct larger scale survey to strengthen the representativeness. According to regression, this research found only "technology cluster" is influencing factor to willingness 
of adoption, and it only explains $28.5 \%$ of total variance. Therefore, future research may consider consumers' needs and characteristics of innovative products as new variables to make dimensions more complete.

\section{References}

1. K. Chen, Some approaches to the development of $3 \mathrm{G}$ mobile in China, 2TE Communications, 30, pp. 40-46 (2004).

2. S. Ming, $3 \mathrm{G}$ mobile: opportunity in the neck of the bottle, China Internet Weekly, Nov (1), pp. 13-17 (2004).

3. W. Gong, $3 \mathrm{G}$ mobile: slipping into the dilemma, Business Watch Magazine, May (1), 24 (2001).

4. E. M. Rogers, Diffusion of Innovations (4th edition). (The Free Press. New York, 1995)

5. Valente and Davis, UMTS Forum Mobile Evolution White Paper, August 2003. Article available on UMTS Forum official website

http:/www.umts-forum.org/servlet/dycon/ztumts/umts/Live/en/umts/3G_index

6. K. Kautz, and J. P. Heje, Diffusion and Adoption of Information Technology (IFIP, Chapman and Hall, 1995).

7. L. Leung, Lifestyles and the use of new media technology in urban China, Telecommunication Policy, 22(9), pp. 781-790 (1998).

8. J. C. Nunnally, Psychometric Theory (McGraw-Hill, New York, 1967).

9. Dutton, H. William, E. M. Rogers, and S. H. Jun, Diffusion and social impacts of personal computers, Communication Research, 14(2), pp. 219-250 (1987).

10. D. J. Atkin, Adoption of cable amidst a multimedia environment, TelematicsandInformatives, $10(1)$, pp. 51-57 (1993).

11. D. J. Atkin, and L. W. Jeffres, Predicting use of technologies for communication and consumer needs, Journal of Broadcasting and Electronic Media, 40(3), pp. 318-331 (1996).

12. S. S. Li, New Types of Non-store Shopping and Their Adopters: Examining the Factors that Influence the Intentions to Adopt Internet Shopping and Cable Television Shopping, Proceedings of Annual Conference of the Association for Media and Communication Research, Barcelona, Spain, 2002.

13. R. Wei, From luxury to utility: a longitudinal analysis of cell phone laggards, Journalism and Mass Communication Quarterly, 78(4), pp. $702-719$ (2001)

14. D. J. Atkin, L. W. Jeffres, and K. A. Neuendorf, Understanding internet adoption as telecommunications behavior, Journal of Broadcasting and Electronic Media, 42(4), pp. 475-490 (1998).

15. C. A. Lin, Exploring personal computer adoption dynamics, Journal of Broadcasting and Electronic Media, 42(1), pp. 95-112 (1998).

16. D. I. Hawkins, R. J. Best, and K. A. Coney, Consumer Behavior: Building Marketing Strategies (McGraw-Hill, New York, 2001). 